\title{
Contributions of Geophysics and Remote Sensing in the Mapping of Hydraulically Active Fractures in the Base Zone West of Kinshasa, DR-Congo
}

\author{
BOLONDA KABEMBA Sandrick ${ }^{1}$, KATAYI KABAMBA Kati ${ }^{1}$, BAKAMUBIA KANYINDA \\ Simon $^{1}$, NSAKALA TANDA Reddy-Andy ${ }^{2}$ \\ ${ }^{1}$ Researcher, Geophysics Research Center (CRG), Kinshasa, DR Congo \\ ${ }^{2}$ Researcher, National Tele detection Center (CNT), Kinshasa, DR Congo
}

\begin{abstract}
The hills region is very famous west of Kinshasa, which is why its drinking water supply problems in the municipalities and various districts of NGALIEMA and MONT-NGAFULA, located in an area made up only of crystalline rocks. She is experiencing acute difficulties in accessing water resources. The objectives of this study is to map fracture networks from satellite images and to use electrical resistivity tomography for their location on the ground. The methodological approach used is based on the use of remote sensing techniques for structural lineament mapping and the application of electrical resistivity tomography for the validation of hydraulically active lineaments. The use of techniques of selective principal component analysis and directional spatial filtering of sobel made it possible to establish the map of major lineaments. The validation of the lineaments was made during several geophysical prospecting work of electrical resistivity tomography. The map generated following the processing of satellite images counts 65 linear structures whose size varies from 7 to $41 \mathrm{~km}$ and which have two preferential directions $\mathrm{NO}^{\circ}-\mathrm{N}^{\circ} 0^{\circ}$ and $\mathrm{N} 80^{\circ}-90^{\circ}$.

At the end of the geophysical work, 10 lineaments were validated as major fractures with altered cracked zone widths ranging from 15 to $40 \mathrm{~m}$ and whose depths are beyond $50 \mathrm{~m}$. The range of electrical resistivity characterizing these fractures varies from 100 to $800 \Omega m$.
\end{abstract}

Keywords: Lineaments, Electrical Resistivity Tomography, Crystalline Rocks, Hydraulic Resources, City Of Kinshasa.

\section{INTRODUCTION}

Having enough and good water on hand is, along with food, one of the most urgent human needs on earth. The scarcity of water causes many tragedies in the communities. In Kinshasa, more particularly in the Kin-Ouest region, located in a crystalline basement area, there is a lack of water in the household to cover daily needs. This is due to the high negative drilling rate of over $40 \%$ and the percentage of drilling with a flow rate of less than $1 \mathrm{~m} 3 / \mathrm{h}$ is around $85 \%$. One of the solutions to these many problems lies in a better knowledge of fracture aquifers.

Crystalline basement rocks and highly metamorphosed metasediments and metavolcanic rocks form local aquifers where they have developed altered and or fractured zones. This generally has low productivity, but sometimes moderate. Transmissivity values of 1 to $50 \mathrm{~m} 2 / \mathrm{D}$, and rarely $100 \mathrm{~m} 2$ / D, have been recorded and yields of 0.2 to 1.7 and rarely from 3 to 5 liters / Sec. (20 to 150 rarely up to $300 \mathrm{~m} 3$ ).

The properties of the aquifer are controlled by the depth of atmospheric alteration (regolith) and the degree of fracturing of the unaltered bedrock. Fractured bedrock sometimes can and cannot sustain these yields over the long term. The altered regoliths (up to $30 \mathrm{~m}$ thick in the city of Kinshasa province in its southwestern part, more precisely in the commune of MONT-NGAFULA and NGALIEMA.

Considered as the Congo Basin Watershed, contains groundwater in the basement aquifer generally have naturally low levels of mineralization and a pH below neutral. Indeed, the work of (PAGIREL 2017) has shown that a more precise knowledge of fractured aquifers is essential for a better location, exploitation and sustainable management of their resources. One of the 
fundamental approaches nowadays in geophysics on the study of fracturing is remote sensing which is a good tool in the study of even the most discrete tectonic discontinuities for hydrogeological prospecting and research of groundwater in environments fractured.

However, the results obtained from the use of remote sensing techniques are confronted with the problems of their reliability and their validation. Remote sensing from space provides information in comprehensive, rapid, quantitative and consistent ways. This underlines the obligation to validate and check the results of the interpretation of satellite images on the ground. Indeed geophysics in general and electrical resistivity tomography imaging in particular, support remote sensing approaches. It makes it possible to determine with better precision the position of geological discontinuities and to locate areas of high hydrogeological interest. The use of a coupled geophysical and remote sensing approach can remedy the lack of data and considerably reduce the uncertainties in the siting of boreholes in the basement area.

The present work therefore aims to map and accurately locate fractured aquifers for better planning of the supply of drinking water to the populations of western Kinshasa. More particularly the commune of MONT-NGAFULA and NGALIEMA.

At the end of the geophysical work, 10 lineaments were validated as major fractures with altered cracked zone widths ranging from 15 to $40 \mathrm{~m}$ and whose depths are beyond $50 \mathrm{~m}$. The range of electrical resistivity characterizing these fractures varies from 100 to $800 \Omega \mathrm{m}$.

\section{PRESENTATION OF THE STUDY AREA}

Kinshasa (in Lingala, Kisásá), called Léopoldville or Leopoldstad (In Dutch) from 1881 to 1966, is the capital and the largest city of the Democratic Republic of Congo (DRC); it covers 9,965 km2. With a population estimated in 2018 at 13.2 million inhabitants, its urban agglomeration is the third most populous in Africa after Cairo and Lagos, and constitutes the largest Frenchspeaking agglomeration in the world, having overtaken that of Paris in the 2010s, and is one of the most populous cities in the world. Located on the south bank of the Congo River, near the MALEBO Pool, it faces the capital of the Republic of Congo, Brazzaville. The study area is located to the west of Kinshasa, in the hills department (containing the towns of NGALIEMA and MONT-NGAFULA). Located between latitudes $4^{\circ} 25^{\prime} 35^{\prime}$ ' 'South and longitudes $15^{\circ} 17^{\prime} 44$ 'West. Borders of the Kongo Central province in the southwest, the towns of KINSENSO and LEMBA in the east and the MALEBO Pool, as well as the Congo river and the bay of NGALIEMA in the north (figure 1). It stretches nearly $58 \mathrm{~km}$ from west to east and covers an area of 3,874 $\mathrm{km} 2$, or $9.8 \%$ of the national territory with a total population of over 48,431 inhabitants.

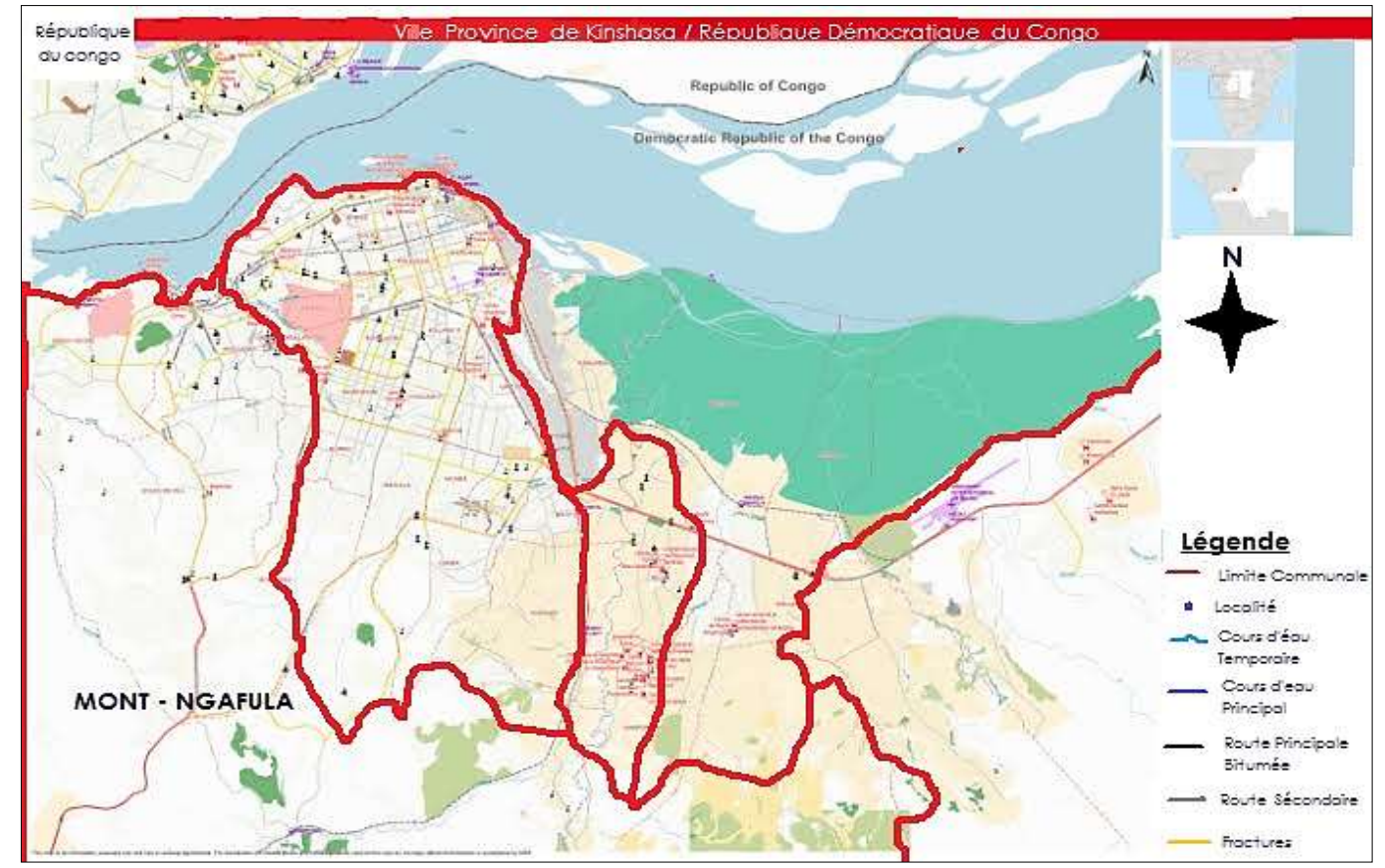

Figure 01: Presentation of the map of the study area 


\section{1. GEOMORPHOLOGICAL POINT OF VIEW}

There is a very rugged rocky peneplain with isolated domes of inselbergs and small chains, the longest of which stretches for nearly $30 \mathrm{~km}$ and picturesque hills. The relief peaks between 150 and $800 \mathrm{~m}$ with slopes varying between 4 and $12 \%$ in the agglomerated sites. The foundations of the geological formations are composed of rocks from the Late Precambrian. This Precambrian is made up of very resistant feldspathic sandstones, belonging to the Inkisi (Schistogresous System) series which extends from the KINSUKA rapids to the BANGU massif in the west in the central Kongo province. The superficial part of these red sandstones is altered in places. The rock, the thickness of which is variable and greater in some places than $500 \mathrm{~m}$, alters at an altitude of $450 \mathrm{~m}$ at the level of the AFRITEC quarry in MITENDI, in the upstream part of the area; while at the level of the LUKAYA river at KIMWENZA in the downstream part, it is found at an altitude of $430 \mathrm{~m}$ (figure 2).

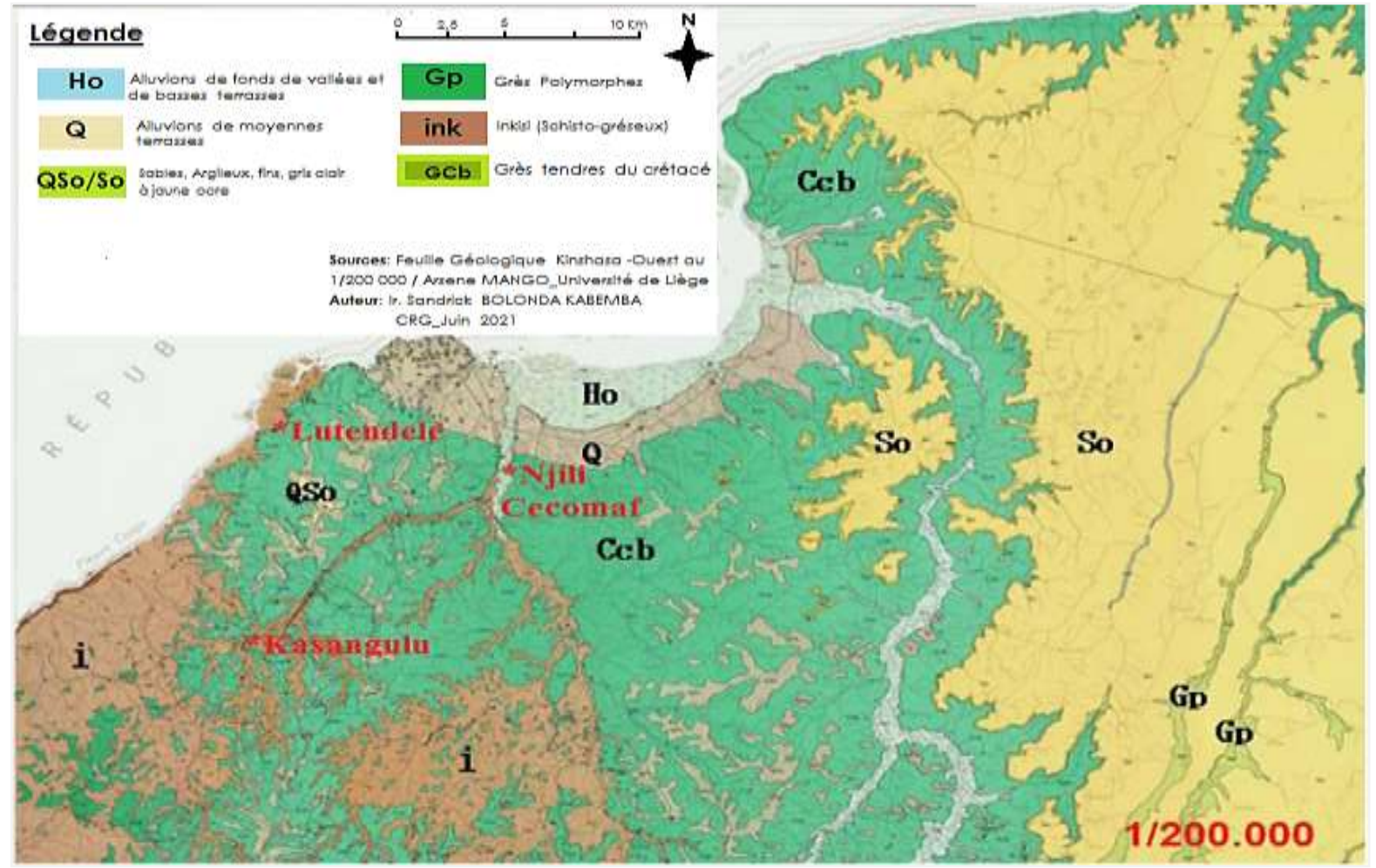

Figure 02: Presentation of the geological map of the study area

\section{2. GROUND POINT OF VIEW}

The basement slope area with its hills and its valleys presents itself as an area entirely made up of a cover of fine sand slightly clayey ocher to brownish: capping the top of the hills and covering with a continuous mantle. The hills appear as a relatively homogeneous whole from the point of view of their composition. It largely determines the suitability of soil runoff, infiltration and evaporation. In the hill and plain zones, the sandy cover is found either on soft sandstone, or on a clayey bench or finally on hard sandstone.

\subsection{GEOLOGICAL AND HYDROGEOLOGICAL POINT OF VIEW}

The study area lies on a subsoil composed of crystalline rocks with low alteration ( 8 to $15 \mathrm{~m}$ on average) and rests on Precambrian material from the old granito-gneissic basement. The work and report (UNEP, May 2016) and (PMEU, December 2019) showed the geological complexity of this study area. It is in fact a litho stratigraphy as shown (figure 03) and a structural set that has undergone some deformation. As for the hydrogeological plan, the zone is characterized by two superimposed reservoirs. These are reservoirs of alterity and reservoirs of fractures also called discontinuous aquifers.

While alterity reservoirs have a primary porosity and a capacitive role due to their clayey-sandy nature, fracture reservoirs are underlying with a secondary porosity playing a transmissive role. the results of numerous boreholes carried out by the hydraulic projects in the urban-rural environment in the sector, show that the alterity reservoirs have a very low thickness between 3 and 8 $\mathrm{m}$ with drilling depths varying between 38 and $80 \mathrm{~m}$, for flow rates from 0.7 to $10 \mathrm{~m} 3 / \mathrm{h}$. the success rate for carrying out boreholes is $30 \%$ to $70 \%$ for village hydraulics and $20 \%$ to $30 \%$ for urban hydraulics (Figure 3 ). 


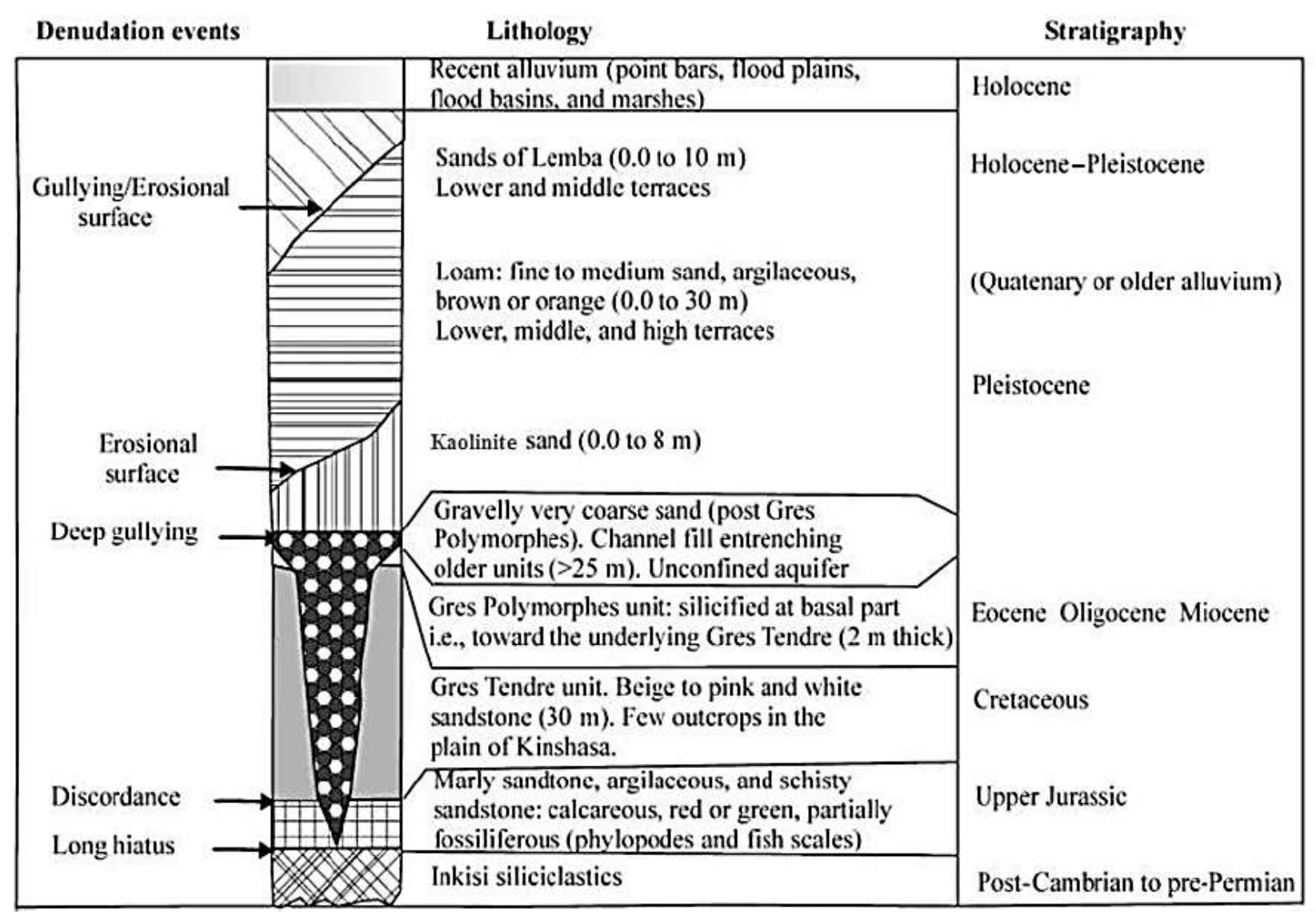

Figure 03: Detailed stratigraphy of the study area

\subsection{METHODOLOGY AND MATERIAL USED}

\subsubsection{Data and Materials for Fracture Mapping}

This study required the use of a 30 x 30 resolution LANDSAT OLI image of a scene (192 - 055). This satellite image was downloaded from the NASA website (http: // landsat.usgs.gouv). Topographic and geographic base maps, all established at a scale of 1: 200,000 by the Geographic Institute of Congo (IGC) in 1980 were used. These data were processed using software such as (QUANTUM GIS and ARC GIS 10.2). After the lineaments were extracted, the different fracture families (in numbers and in cumulative lengths) were processed with RockWorks 16 software.

\subsubsection{Data and Materials for Linear Validation}

The data used in this study consist of 5 panels of TRE (Electrical Resistivity Tomography) carried out on major lineaments identified after the application of techniques for extracting them by remote sensing. Resistivity tomography work was done during the months of April, May, and June 2021 and in 3 areas after image processing. TRE's prospecting equipment for collecting data in the field, is made up of a SYSCAL R2 and SWICTH 48 with its accessories (connection coils, electrodes, mass hectometers, a compass, a GPS, clamps Crocodiles, a DC / DC electric voltage converter, a $12 \mathrm{~V}$ battery, etc.). the processing of the geophysical data was carried out by the software supplied with the equipment such as the PROSYS II and DC2D INVRES. 


\section{METHODOLOGY}

The methodological approach used in this study can be summed up in 2 Steps. First, the remote sensing method applied to images for structural mapping. Then, the use of geophysical prospecting by TRE to locate fractures on the ground.

\subsection{Remote sensing approach for lineament mapping}

The methodology to be followed for the identification of the fracture network in the study area comes down to the preprocessing of satellite images (radiometric correction), to the accentuation of structural discontinuities and finally to the extraction of lineaments present on the image. . The use of several digital processing methods applied to Landsat OLI 8 images using image fusion techniques (APCS) and directional spatial filtering techniques have resulted in increasing the perception of the image by improving it. and making it more expressive and sharper.

\subsubsection{OLI Image Preprocessing}

The satellite image preprocessing phase consists of eliminating radiometric noise in the bands, providing a very wide range of transformed images and facilitating their interpretation.

The Landsat OLI images are previously georeferenced and geometrically corrected. Only radiometric corrections were made on these images. This correction eliminated radiometric noise in the Landsat OLI bands. The radiometric correction was carried out on the one hand, by the application of the Fourier transform (Smirnov, 1992) on the panchromatic channel of OLI and the OLI band 5 of Landsat and on the other hand, by the use of low pass filters (Moore and Waltz, 1983).

The correction of the atmospheric effect and the relief was made to reduce the effect of haze, assimilated to an additive factor on the radiometric signal, of these bands, the technique proposed by NASA (American National Space Agency) was adopted in this study. The resampling of the pixels of the panchromatic bands (Landsat OLI 8) was also necessary to reduce the pixels from $60 \mathrm{~m}$ to $30 \mathrm{~m}$ apart. The bilinear interpolation method was used. The corrected images underwent further processing to improve visual perception for better mapping of geological accidents in the study area.

\subsubsection{OLI Image Processing}

Selective principal component analysis technique In order to map as many discontinuities as possible that affected the study area, the technique of selective principal component analysis (ACPS) was applied. It consisted in carrying out a first ACPS with the visible bands, which made it possible to obtain the various components.

\subsubsection{Directional spatial filtering technique of lineaments}

Spatial filters are another digital processing method used for enhancing an image. These filters gave very good results during the structural study of the soil of the watershed of the river LUKAYA on the project: Action plan for the integrated management of water resources of the watershed of the river LUKAYA (PAGIREL, 2016 -2018). Within the framework of this study, the technique of filtering by moving window (1024x1024) was used in order to accentuate the structural discontinuities by means of the spatial filters designed for this purpose. In the present study, directional filters (Sobel type of size 7x7) were applied on Landsat OLI4, OLI6 bands and selective principal component analysis (ACPS).

\subsection{Approach to the technique of geophysical prospecting}

For the investigation of the field work of this study, the data acquisition mode is programmed according to the dipole-dipole configuration. Indeed, the work of several authors such as: (Baltassat et al, 2017), Roques, (2013), (Alle et al, 2018) have shown that the dipole-dipole (DD) configuration offers good resolution of subsurface and vertical and horizontal discontinuities. The data acquisition sequences are programmed using the PROSYS II software. Field investigations are carried out with profiles of $240 \mathrm{~m}$ for an inter-electrode distance of $5 \mathrm{~m}$, ie 48 electrodes in total. The 5 electrical panels are installed on 3 sites.

These panels all have the same lengths with different orientations while remaining perpendicular to the lineaments. The measurement parameters (number of repetitions (stacks), injection time, acceptable error, measurement mode) are defined and programmed in the measuring device. The profile measurements are filtered and processed using the X2IPI software, then inverted with the RES2DINV software while integrating the topography along the profiles. For a good comparison of the different electrical panels, it was chosen and applied a color scale for the different ranges of resistivities (between 5 and $4000 \mathrm{Ohm}$. $\mathrm{m}$ ) to the whole of the basement imagery in the area study. Figure 4 shows the prospecting areas and the orientation of the TRE profiles. 


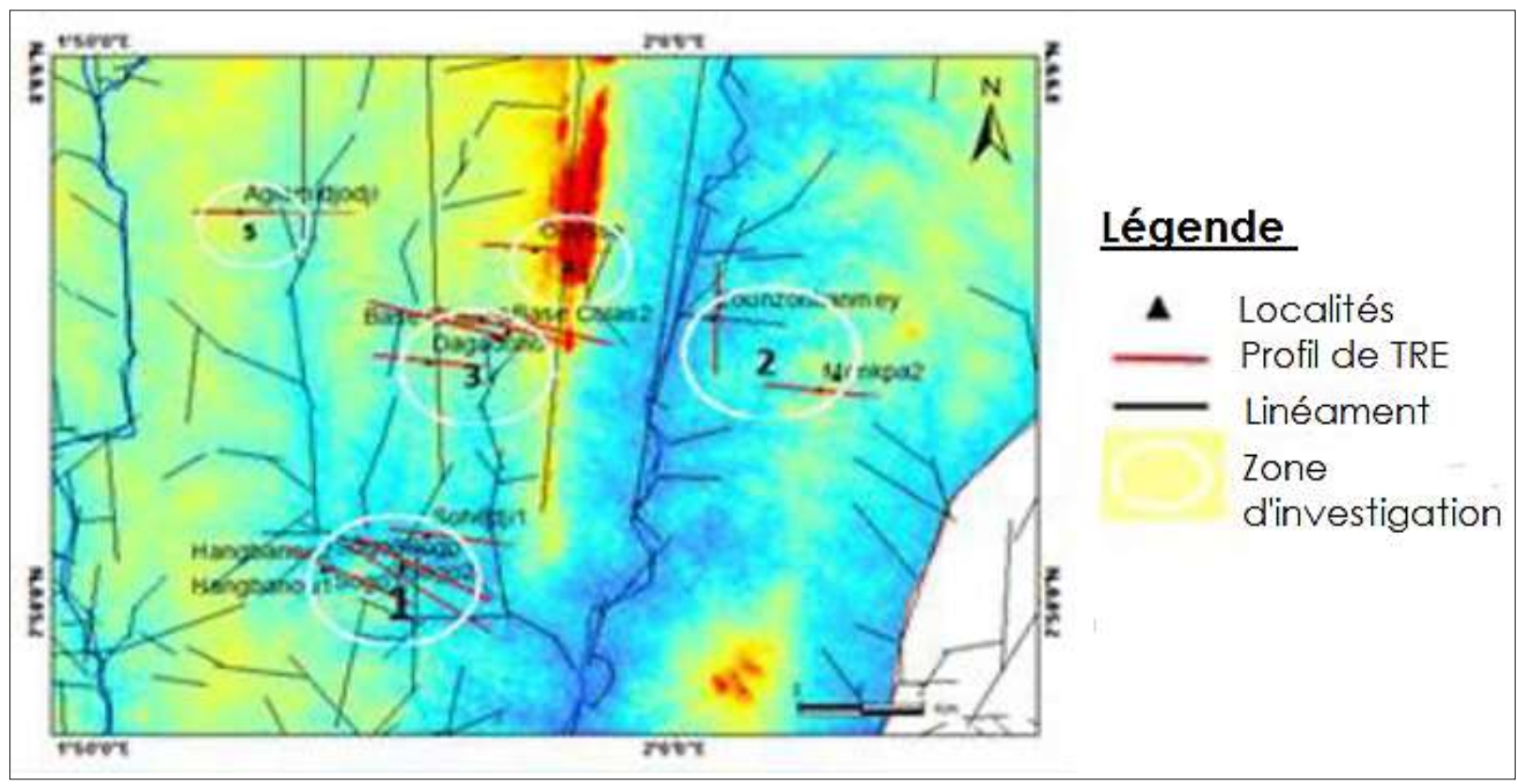

Figure 04: Présentation of prospecting areas and orientation of TRE profiles

Fieldwork for lineament validation using ERT was carried out in the five (5) zones. These zones are chosen according to the geological formations, the density of lineaments, the proximity of localities or rivers. They are numbered from 1 to 5 without any priority. Thus, 06 major lineaments were identified on the lineament map and were the subject of geophysical prospecting.

\section{Lineament Remote Sensing Results}

\section{1. Mapping of regional lineaments using remote sensing}

The use of Sobel filters of dimension 7 x7 on the ACPS (figure 4) and the ACPS (figure 5) made it possible to highlight numerous structural lineaments located in the center-west of Kinshasa. Figure 5 presents all the major lineaments resulting from the interpretations of the images derived from the different processing techniques.

These lineaments have variable sizes and directions that can reach several kilometers. The analysis of Figure 6 shows that $51 \%$ of the lineaments are between 4 and $12 \mathrm{~km}$ in size, $35 \%$ of the lineaments are between 12 and $25 \mathrm{~km}$ in size, and about $14 \%$ of the lineaments exceed $30 \mathrm{~km}$ in length.

This study made it possible to map several geological discontinuities, the main ones of which are:

$>$ The lineament of MBUDI (L01 MBDI) of direction N0 ${ }^{\circ}$;

$>$ The lineament going from KIMBUALA to MALUEKA (L02 KL-MK) with direction N $10^{\circ}$;

$>$ The lineament of SAFRICAS (L03 SAF) of direction N0 ${ }^{\circ}$;

$>$ The lineament of CPA (L04 CPA) of direction N 70;

$>$ The lineament of LUTENDELE (L05 LTLE) of direction N 80;

$>$ The lineament of MUSHI (L06 MSHI) of direction N10; 


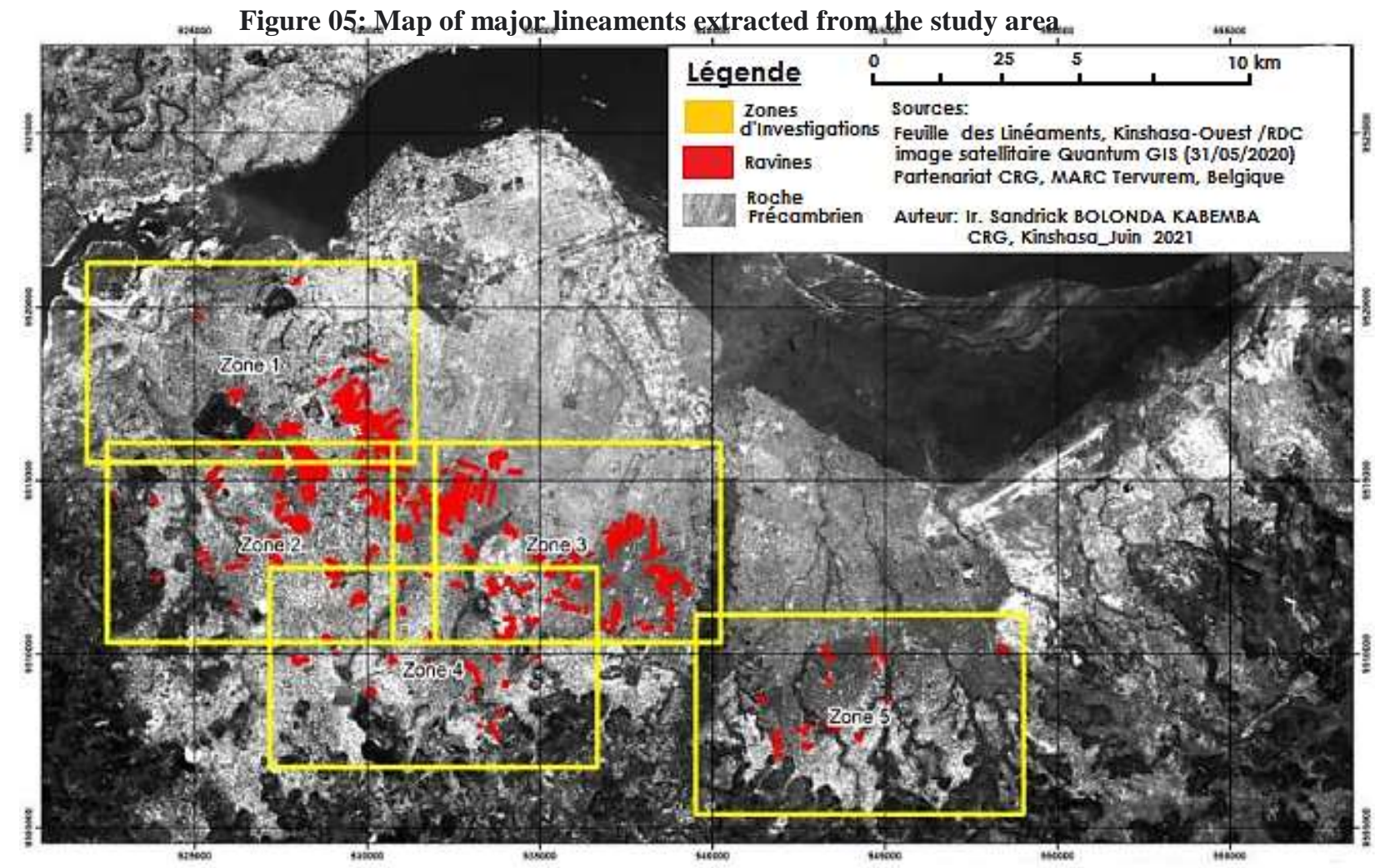

Figure 05: Map of major lineaments extracted from the study area

The major lineaments are grouped into classes according to their orientation following angular growths of 10 degrees on a directional rosette. The directional analysis of the fracturing of the South-West of the Collines Department in cumulative numbers and lengths (Figures 06a and 06b) shows a certain homogeneity of the fracturing. The most abundant fractures (N-S and E-W) are also the longest. The dominant classes of fracturing in numbers (Figure 06 a) show two predominant directions, it is respectively the direction $\mathrm{N} 0{ }^{\circ}-10^{\circ}(\mathrm{NS})$, largely dominant, representing more than $6 \%$ in frequency of fractures in number and the direction $\mathrm{N} 80^{\circ}-90^{\circ}(\mathrm{EW})$, dominant, representing more than $4 \%$ in number fracture frequencies. The other classes whose frequencies are less than $4 \%$ are considered to be in the minority.

Regarding the cumulative length distribution, no fracture class exceeds $10 \%$. The distribution of fractures in the center-west of Kinshasa can therefore be described as uniform. However, two classes of leadership stand out from the whole. 

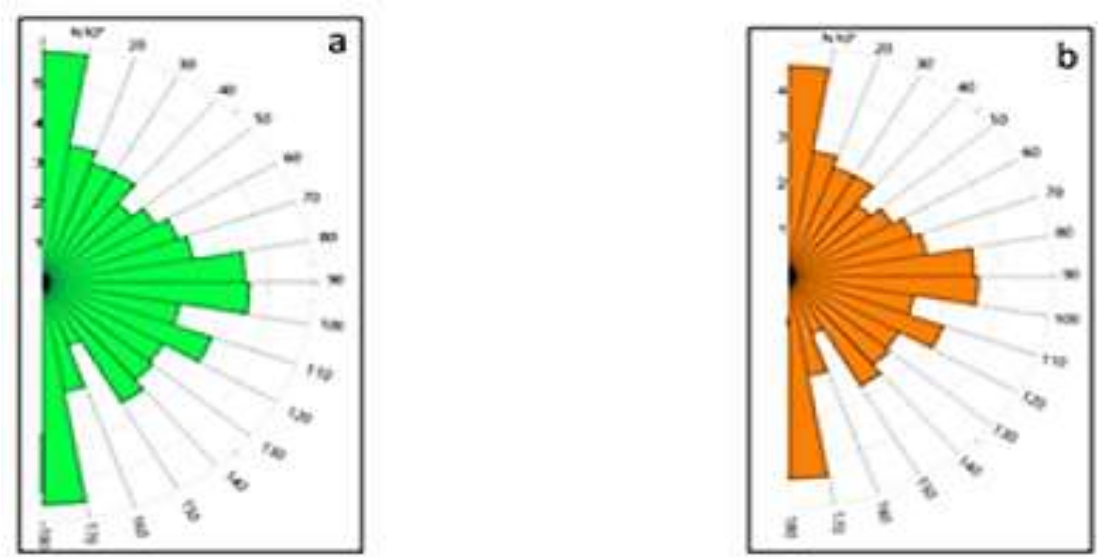

Figure 06: Directional rosettes of lineaments in the southwest of the Collines Department of Kinshasa: a- Frequency in number of lineaments; b- Frequency in cumulative lengths.

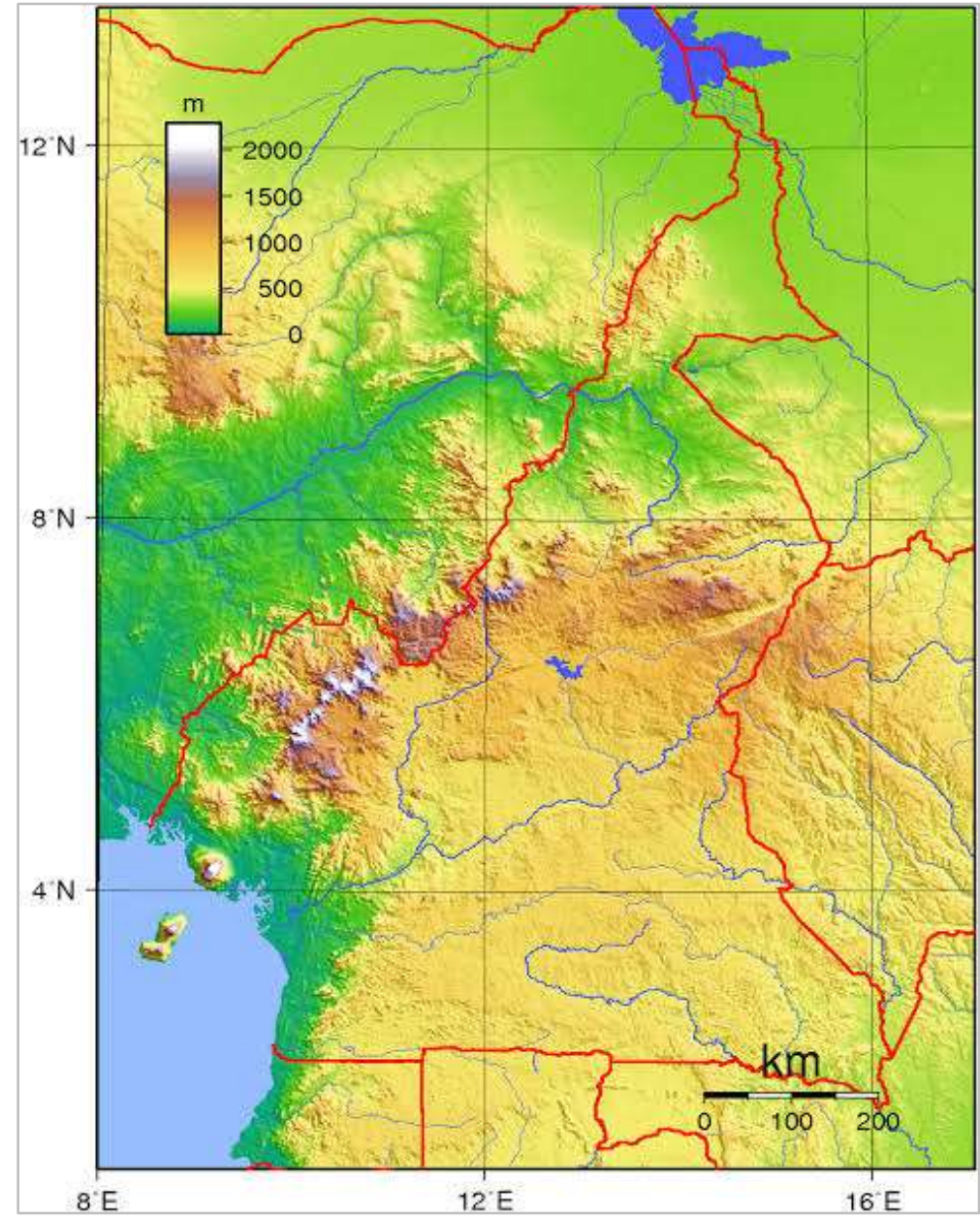

Figure 07: Sobel of direction N-S and E-O heightening The E-O and N-S Lineaments 


\section{Results of the Geophysical characterization on Lineaments}

For the present study, only the results of 5 panels are presented and interpreted. However, Table 01 presents the synthesis of the results of the 05 zones after the geophysical prospecting works.

\section{MBUDI site in zone 1}

The electrical resistivity imaging of the subsoil in Figure 7 is obtained from the MBUDI Zone 1 site (Figure 8).

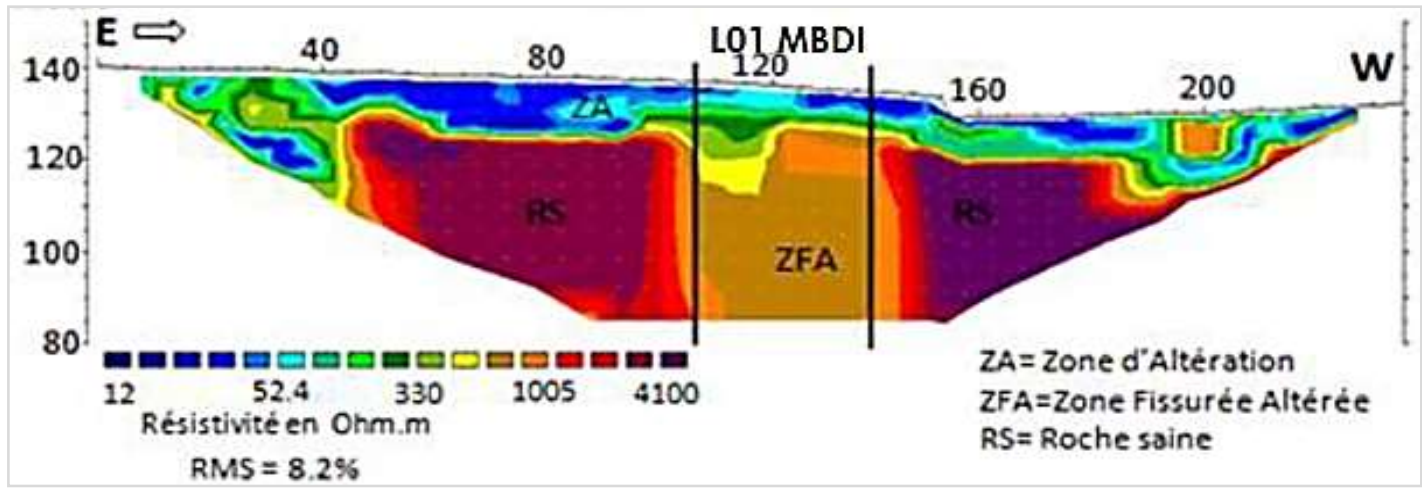

Figure 08: TRE panel (Electrical Resistivity Tomography): MBUDI site (zone 1)

The MBUDI zone 1 site. The profile is made perpendicular to the Lineament (L01 MDI). The electrical resistivity panel has Resistivity ranges varying from 12 to $4200 \Omega \mathrm{m}$. This range of resistivity can be divided into 3 sub-ranges corresponding to different important geological layers of the subsoil. Indeed, observation of the electrical resistivity panel shows a first horizontal layer (1) $8 \mathrm{~m}$ thick along the oriented conductive profile with low resistivities ranging from 12 to $70 \Omega \mathrm{m}$ corresponding to the range I. Under the first surface layer, electrical imaging of the subsoil clearly shows a thin layer of thickness varying between 0.5 to $5 \mathrm{~m}$ all along the profile. This second layer (2), which is not very resistant with resistivities of $350 \Omega \mathrm{m}$ on average, can reach a depth of $20 \mathrm{~m}$ to the east, and to the west of the profile. Under the second structure, we have the third layer (3) made up of very resistant blocks (1500 to $4000 \Omega . \mathrm{m}$ ) and crossed by a less resistant corridor (450 to $800 \Omega \mathrm{m}$ ) between the abscissas 105 and $138 \mathrm{~m}$ to the right of the lineament that is the center of the measures. The thickness of this last layer is not known (>50 m) due to lack of depth of investigation. Thus, the lineament (L03) seen at the surface by remote sensing is also seen in depth by TRE with a width of $32 \mathrm{~m}$.

\section{KIMBUALA and MALUEKA sites in zones 2 and 4}

Electrical imaging (Figure 8) of the KIMBUALA and MALUEKA zone 2 and 4 site intersects the lineaments L02 KMLA and L02 MLKA. It has resistivity ranges varying from 12 to $4300 \Omega \mathrm{m}$. This resistivity range can be divided into 3 sub-ranges corresponding to the different geological layers. Indeed, there is a first very conductive surface layer (1) $10 \mathrm{~m}$ thick all along the E-W oriented profile with low resistivities ranging from 12 to $70 \Omega \mathrm{m}$; (figure 9)

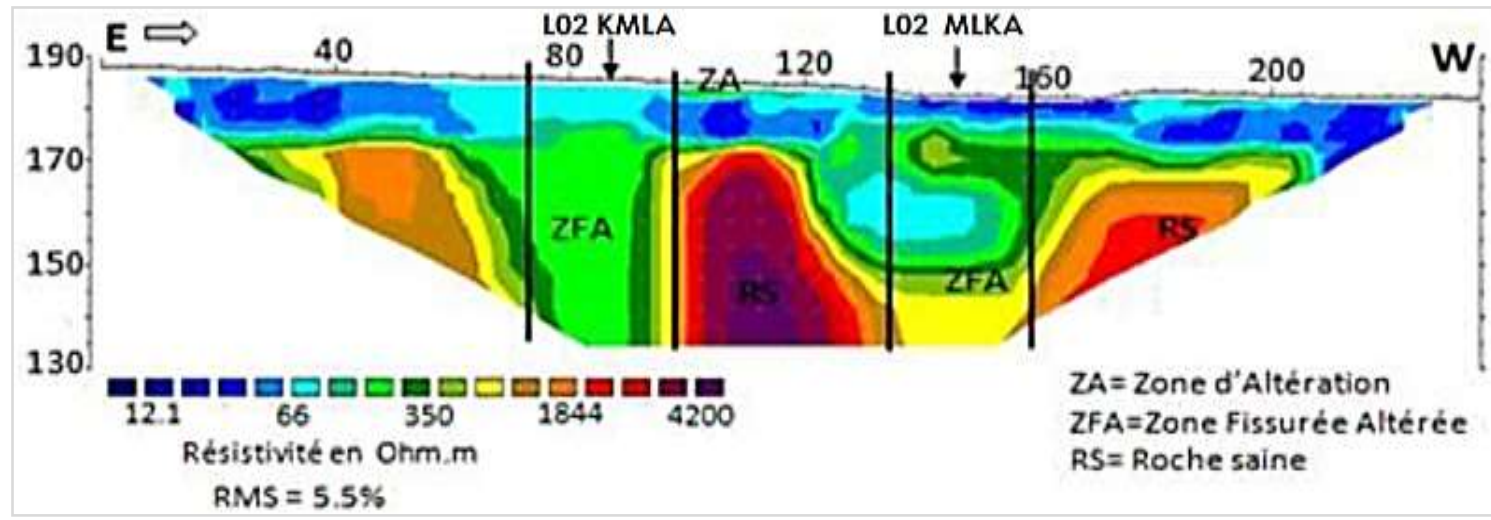

Figure 09: TRE panel: KIMBUALA and MALUEKA site (zone 2 and 4) 
Below, there is a second layer (2) of variable thickness which may exceed 50 m locally directly above the lineaments (KLA and MKA) between the abscissas 73 to $98 \mathrm{~m}$ and between 135 to $160 \mathrm{~m}$ with average resistivities ranging from 100 to $1000 \Omega \mathrm{m}$. Finally, the very resistant layer (3) with very high resistivities varying between 1000 to $4300 \Omega \mathrm{m}$ is very superficial between the abscissas 20 to 73,98 to 134 and 160 to $200 \mathrm{~m}$. On the profile imagery carried out at KIMBUALA and MALUEKA, a total of 3 terrains (layers) can be observed, all coming from the transformation to varying degrees of the bedrock. The two lineaments observed on the satellite image are clearly visible on the electrical panel produced.

\section{SAFRICAS site in zone 3}

Electrical imaging (Figure 09), carried out on the SAFRICAS zone 3 site and secant to the L03 SAF lineament, shows resistivity ranges varying from 10 to $4000 \Omega \mathrm{m}$. This resistivity range can be grouped into 3 sub-ranges representing different geological layers. The first surface layer (1), 12 m thick, is highly conductive all along the E-W oriented profile. It has very low resistivities ranging from 12 to $150 \Omega \mathrm{m}$ corresponding to the 1 range.

Below this layer 1, there is a thin horizontal layer of low thickness 2 to $5 \mathrm{~m}$ with resistivities ranging from 150 to $400 \Omega \mathrm{m}$. At the level of layer (3), we observe a very resistant structure of around $4000 \Omega \mathrm{m}$, the thickness of which is infinite. The third and the second layer are crossed between the abscissas 130 and $155 \mathrm{~m}$ by a corridor of the same resistivity as the first layer; (figure 10).

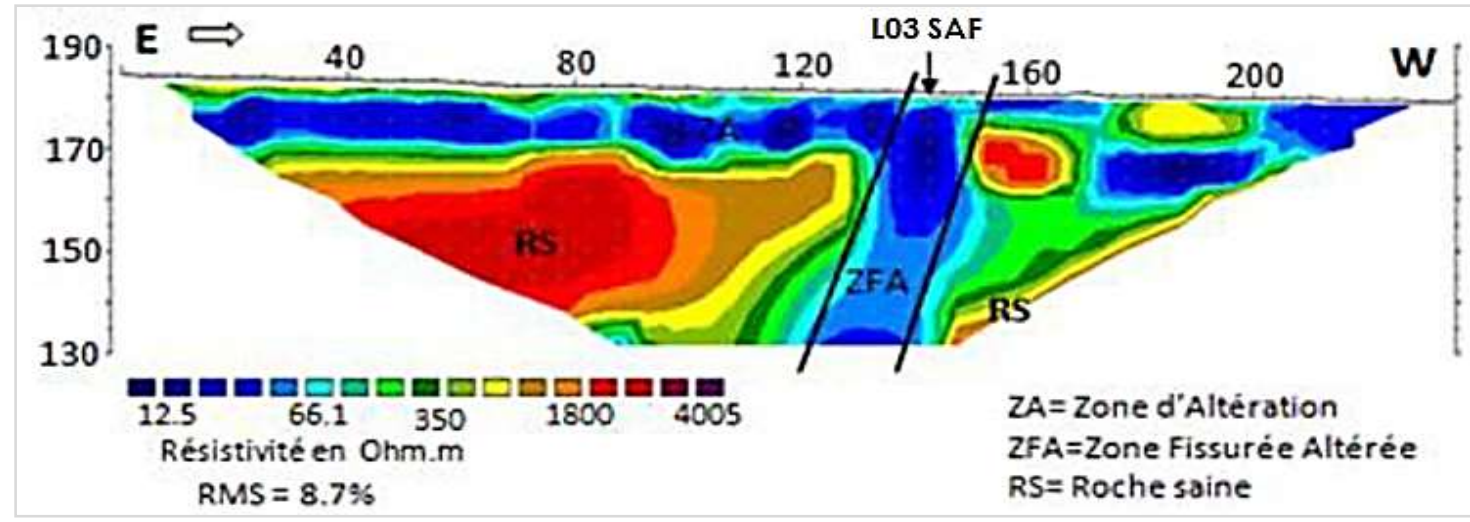

Figure 10: TRE panel: SAFRICAS site (zone 3)

The bedrock of this corridor is invisible in the image in Figure 09.

This corridor $15 \mathrm{~m}$ wide on average is the manifestation of the L4DH lineament in the basement.

\section{LUTENDELE site in zone 5}

The image in Figure 10 produced on the LUTENDELE site in zone 5 secant to the L 05 LTLE lineament has resistivity ranges from 10 to $4000 \Omega \mathrm{m}$. This resistivity range can be grouped into 3 sub-ranges representing different geological layers. The first superficial layer (1) with a thickness varying from 5 to $15 \mathrm{~m}$. The thickness of this layer varies along the E-W oriented profile and can reach $20 \mathrm{~m}$ in places. It is very conductive with resistivities lower than $100 \Omega \mathrm{m}$ (range I). Under the first, there is a second (layer 2) horizontal which is distinguished by an electrical resistivity ranging from 100 to $800 \Omega \mathrm{m}$ (range II) with a variable thickness between 2 and $10 \mathrm{~m}$ along the profile (figure 11).

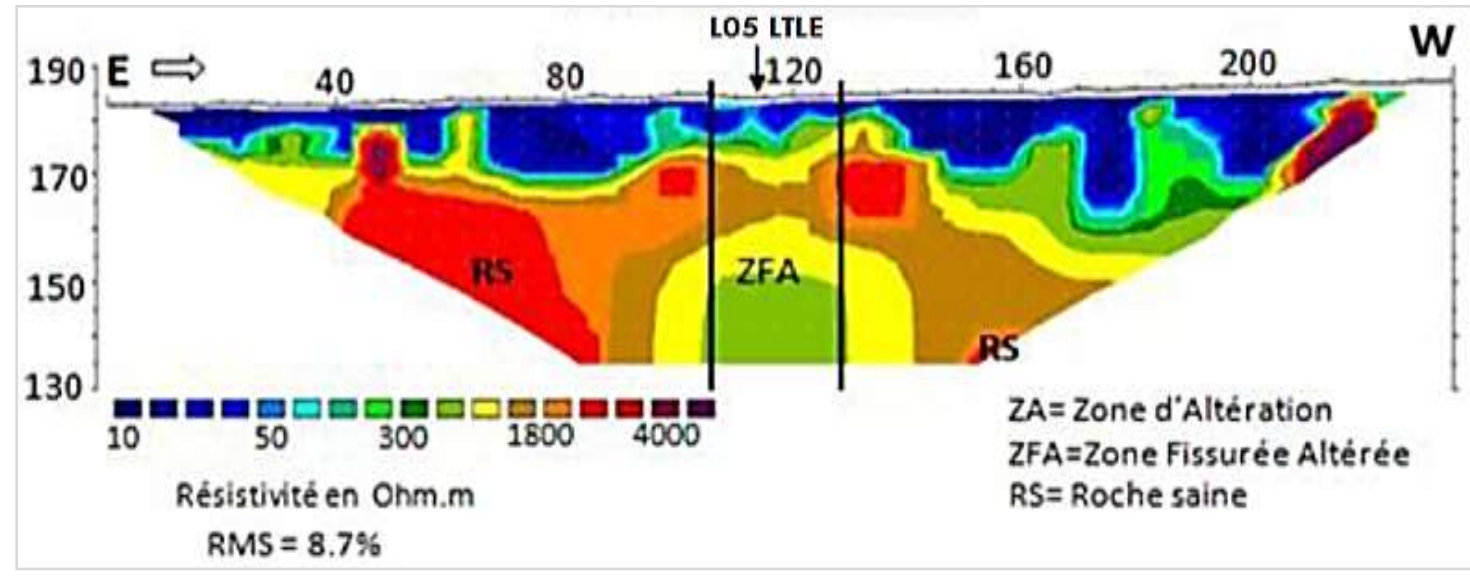

Figure 11: TRE panel: LUTENDELE site (zone 5) 
The third layer, always horizontal, has resistivities ranging from 1800 to $4000 \Omega \mathrm{m}$ (range III) as indicated in FIG. 10. This third layer is crossed by a corridor of resistivity identical to that of the second layer. Indeed, the desired lineament (L05 LTLE) is much more visible on this electrical resistivity panel than from a depth of $20 \mathrm{~m}$. This is due to a strong alteration of layer 3 at this depth with a width of approximately $24 \mathrm{~m}$. Table 2 presents the characteristics of the lineaments prospected during the TRE campaign for their fracture validation. In view of the information contained in this table, we note that the orientation, the dip, the ranges of resistivities, the width not to mention the thickness of the alteration overlap at the level of the different fractures vary according to the sites investigated.

All lineaments identified in the 5 zones were validated by electrical resistivity tomography. Analysis of the table indicates that the lineaments mapped are all linear geological structures with features clearly visible in $2 \mathrm{D}$. Thus, for these structures there are two main directions which are the North-South (NS) and the East-West (E- W) with dips ranging from 0 to $10^{\circ} \mathrm{E}$ for the direction NS and dips of 70 at $90^{\circ} \mathrm{S}$ for EW directions. The opening (width) of the fractures in the study area varies from 15 to $40 \mathrm{~m}$.

It should be noted that all these fractures are surmounted by a small thickness of alterite ( $7 \mathrm{~m}$ on average) originating from the alteration products either of garnet gneiss, or of biotite gneiss or of gneiss linked to the main geological formations of the zoned. The resistivity range reflecting the presence of linear geological structures at the surface and corresponding to the fracture corridors in the subsoil varies from 100 to $800 \Omega \mathrm{m}$. These fracture corridors all have depths of more than $50 \mathrm{~m}$, the limit of the investigation depth of the equipment used (TRE with 48 electrodes).

Table 01. Summary of the results of the electrical resistivity panels on the ground on the 06 major linéaments validated.

\begin{tabular}{|c|c|c|c|c|c|c|c|}
\hline \multirow[b]{2}{*}{ Lineament } & \multicolumn{2}{|c|}{ Contact Informations } & \multirow[b]{2}{*}{ Orientation } & \multirow{2}{*}{$\begin{array}{c}\text { Hangin in } \\
\text { Degree }\end{array}$} & \multirow{2}{*}{$\begin{array}{l}\text { Gr en } \\
(\Omega \mathrm{m})\end{array}$} & \multirow{2}{*}{$\begin{array}{c}\text { Width } \\
\text { m }\end{array}$} & \multirow{2}{*}{$\begin{array}{c}\text { E.A } \\
\text { m }\end{array}$} \\
\hline & Long. & Lat. & & & & & \\
\hline L01 MBD & 1,93468 & 7,85005 & $\mathrm{~N}-\mathrm{S}$ & $0 \mathrm{E}$ & 250 à 800 & 30 & 6 \\
\hline L02 KML & 2,04181 & 7,90053 & $\mathrm{~N}-\mathrm{S}$ & $0 \mathrm{E}$ & 250 à 800 & 25 & 5 \\
\hline L03 SAF & 1,92921 & 7,90945 & E-W & $70 \mathrm{~S}$ & 150 à 750 & 25 & 5 \\
\hline L04 CPA & 1,95975 & 7,9446 & E-W & $80 \mathrm{~S}$ & 200 à 450 & 38 & 8 \\
\hline L05 LTLE & 1,90036 & 7,84567 & E-W & $10 \mathrm{E}$ & 200 à 600 & 15 & 7 \\
\hline L06 MSHI & 1,94916 & 7,92043 & E-W & $70 \mathrm{~S}$ & 100 à 750 & 25 & 8 \\
\hline
\end{tabular}

Gr = Resistivity Range; $\mathbf{E A}=$ Thickness of Otherness; $\mathbf{L}=$ Longitude Lat $=$ Latitude

\section{Discussion on Remote Sensing and Structural Lineament Mapping}

The various specific processing techniques applied to Landsat OLI images, namely ACPS and directional spatial lineament filtering techniques have resulted in the production of the map of major lineaments of the Center-West of Kinshasa. These lineaments have two major directions namely: the N-S direction and the E-W direction.

The directional filters used in the present study made it possible to highlight several linear structures in the study area, for example the lineaments of CPA (L02 CPA) of MBUDI (L03 MBDI) of SAFRICAS (L04 SAF). Little was known about these lineaments until now because they were never mapped in previous studies. The lineaments mapped in this study of North-South direction, parallel to the elongation of geological structures, were put in place during the compression phase of the Pan-African orogeny. They are therefore generally clogged. On the other hand, the transverse lineaments of the geological structures are open and therefore more productive.

Rather, it is the NE-SW and SE-NW directions that are most favorable to hydraulically active fractures and not the meridian or submeridian directions. Likewise, (Engalenc, 1984) quoted by the same author, the perpendicular direction (N-S to NNW-SSE) is also favorable for carrying out high-flow boreholes in the sector. 


\section{Validation of lineaments by electrical resistivity tomography}

In general, the ground imagery of the 12 profiles show that the geological structure of the study area seems to be the same. Thus, in the study area there are three layers. On the surface, we have a thin horizontal structure with a thickness of $7 \mathrm{~m}$ on average and very conductive with resistivities less than $150 \Omega$.m. This structure is layer 1 corresponding to the weathered zone (ZA) of the rock probably made up of a mixture of sand and clay. Under this first layer, we can see an underground environment made up of a horizontal geological structure differentiated on ERT imagery by average resistivities between 150 and $800 \Omega \mathrm{m}$ with low thicknesses between 1 and $15 \mathrm{~m}$. This geological structure (layer 2) found on all the electrical panels undoubtedly represents the altered fissured zone (ZFA). This cracked zone may be deep in the adjacent sub-layer called layer 3 in places. Layer 3 as seen on the imaging of the various electrical panels, with very high resistivities which can go beyond $4000 \Omega$.m testifies to the healthy nature of the rock (RS). However, the healthy rock is crossed in places by deep fracture corridors following tectonic movements.

Indeed, it is these corridors of deep fractures that are clearly materialized by the major lineaments on the surface after processing the satellite images. These lineaments-fractures (fracture corridors or discontinuities) are recognized on imaging by an area of average resistivity 150 to $800 \Omega$.m deep in a very resistant block with resistivities of $4000 \Omega \mathrm{m}$. Thus, the fracture corridors found on all the sections of TRE carried out in the study area testify to the effectiveness of many fractures. These fracture corridors have openings (widths) varying from 15 to $40 \mathrm{~m}$. The depth of these fracture corridors (CF) as well as the sound rock roof (RS) are not known in this study by default investigative depth of the TRE (maximum depth $50 \mathrm{~m}$ ). This reflects the great depth of the fractured-weathered zone. These fracture corridors are the locations sought during geophysical prospecting campaigns for the siting of future boreholes. With the joint contribution of remote sensing and geophysics (TRE), locating fracture corridors becomes easier and safer in crystalline basement areas. It is therefore desirable that practitioners of drilling installation in the middle of the base appropriate this methodology to avoid hazardous installations with these consequences on the economic and social level.

In double porosity / double permeability environments such as crystalline basement areas, the characterization of each portion is restrictive but essential for the mobilization of the related groundwater. For (Roques, 2013) the detailed description of the aquifer structures in these zones by geology and by geophysical imagery is an essential objective for the understanding of fractured reservoirs. Guided by the results of identifying major linear structures on Landsat 8 satellite images and then geophysical investigations by ERT, this made it possible to identify and confirm the geological discontinuities in the study area. The lineaments extracted from the images therefore correspond to the fractures in the field.

Many similar works by different authors: (Savané, 1997; Kouamé, 1999), Jourda, et al, 2006, Descloitres et al, 2008, Soro et al, 2017, Alle et al, 2018) carried out in the same context have resulted in to the precise localization of fractures resulting from specific treatment techniques of remote sensing in crystalline rocks. The results obtained from this work offer a good compromise in terms of localization of tectonic fractures in the field between remote sensing and ERT.

Contrary to the work of Soro et al (2017) in Sanon in Burkina Faso, remote sensing and ERR have made it possible to locate and identify the fracture corridors in the southwest of the hills department in Benin. Thus, with electrical resistivity imaging of the subsoil, it would be possible to drill holes in the fractures that will be more productive Alle et al, (2018). The present approach is more reliable in increasing the probability of success during drilling siting work in a crystalline basement area. Knowing the characteristics and geometry of the fracture, the borehole will ideally be implanted in the bed of the fracture. 


\section{CONCLUSION}

This work took into accourt two activities, namely, the extraction of structural lineaments from the processing of satellite images by specific remote sensing methods and the precise location on the ground of these structural lineaments by geophysical prospecting, in particular ERT. Remote sensing work in central-western Kinshasa shows that a vast network of major lineaments exists. This network is composed of several major lineaments, but we have taken into account 6 surface lineaments with directions, the most representative of which are those of the $\mathrm{N}-\mathrm{S}\left(0-10^{\circ}\right)$, E-W $\left(70-90^{\circ}\right)$ direction classes. As for the investigation work of the TRE, 05 profiles of electrical panels were produced more or less perpendicular to the lineaments.

Electrical resistivity imaging of these panels validated 06 lineaments in fractures in the basement. These fractures have openings 15 to $40 \mathrm{~m}$ wide with depths of more than $50 \mathrm{~m}$. These fractures are probably potential reservoirs of groundwater in this area, which must be located at all costs for better planning of the supply of drinking water to populations. We intend to continue the investigations by carrying out boreholes in a few areas identified in this study in order to compare the results obtained with those of the drilling work.

\section{ACKNOWLEDGMENT}

This study was carried out thanks to the Project "Action Plan for the Integrated Management of Water Resources in the Watershed of the LUKAYA River, (PAGIREL). "Funded by the Congolese State through MECNDD, REGIDESO, and the international partner UNEP. The contents of this paper are the sole responsibility of the authors who would like to thank and express their gratitude to the anonymous instructors for their criticisms, comments and suggestions which have contributed to the improvement of this document. The authors would also like to thank the officials of the Association of Users of the Watershed of the River LUKAYA (AUBR / LUKAYA) who agreed to accompany us for the fieldwork.

\section{BIBLIOGRAPHICAL REFERENCES}

[1]. Adissin Glodji L. (2012). The Kandi shear zone and associated magmatism in the Savalou-Dassa region (Benin): structural, petrological and geochronological study. Earth Science. Jean Monnet Saint-Etienne University; University of Abomey-Calavi (Benin), 277 p.

[2]. Affaton P. (1987). The Voltas Basin (West Africa): a passive margin from the Upper Proterozoic tectonized to the PanAfrican. State thesis, volume 2, University of Aix-Marseille, 449 p.

[3]. Boukari M. (1982). Contribution to the hydrogeological study of the basement regions of intertropical Africa: the hydrogeology of the Dassa-zoumè region (Benin). Thesis University of Dakar, 137 p.

[4] Akokponhoué H. B., Yalo N., Adissin Glodji L., Alassane A., Agbahungba G., Lasm T. (2018). Structural maps of major geological accidents of the crystalline basement of the Donga department (North-West of Benin): Contribution of landsat-8 Oli images and field data. Int. J. of Innovation and Applied Stu, Vol. 24 No. 3 Oct. 2018, pp. 1266-1283.

[5]. Alle C., Descloitres M., Vouillamoz J.M., Yalo N., Lawson F.M.A., Adihou A. C. (2018). Why 1D electrical resistivity techniques can result in inaccurate siting of boreholes in hard rock aquifers and why electrical resistivity tomography must be preferred: the example of Benin, West Afric, Journal of African Earth Sciences 139, 341-353 p.

[6]. Baltassat J-M, Maurice B., Reninger P-A (2017). Electrical resistivity tomography applied to the installation of AEP boreholes on sites in Mayotte. Final report. BRGM / RP- 67169-FR, 71 p., 32ill, 4 tabl, 14 ann. Biemi J. (1992). Contribution to the geological, hydrogeological and remote sensing study of the sub-Saharan watersheds of the Precambrian basement of West Africa: 
[7]. Hydrostructural, hydrodynamic, hydrochemical and isotopy of discontinuous aquifers of furrows and granite areas of Haute Marahoué (Ivory Coast). Doctoral thesis. ès Sc. Nat.Univ Abidjan, 493 p.

[8]. Boukari M. (1982). Contribution to the hydrogeological study of the basement regions of intertropical Africa: the hydrogeology of the Dassa-zoumè region (Benin). Thesis University of Dakar, 137 p.

[9] Boussari W.T. (1975). Contribution to the geological study of the crystalline basement of the Pan-African mobile zone (central region of Dahomey). 3rd cycle thesis, Univ. Besançon., 105 p.

[10]. Breda, 1989. The Explanatory note of the geological map at 1/200000.

Pira-Savè, Abomey-Zagnanado, Lokossa-Porto-Novo sheets, 77p.

Corresponding Author: Sandrick BOLONDA KABEMBA Tel. : +243810535134

E-mail: sandrick_bolonda@yahoo.fr ; sandrickbolonda@gmail.com 